\title{
Optimal Energy Management for Virtual Power Plant with Renewable Generation
}

\author{
Yuchang Kang, Kwoklun Lo, Ivana Kockar \\ University of Strathclyde, Glasgow, United Kingdom \\ Email: Yuchang.kang@strath.ac.uk
}

How to cite this paper: Kang, Y.C., Lo, K.L. and Kockar, I. (2017) Optimal Energy Management for Virtual Power Plant with Renewable Generation. Energy and Power Engineering, 9, 308-316. https://doi.org/10.4236/epe.2017.94B036

Received: February 17, 2017

Accepted: March 30, 2017

Published: April 6, 2017

\begin{abstract}
The nature of variable and uncertainty from renewable energy sources (RESs) makes them challenging to be integrated into the main grid separately. A Virtual Power Plant (VPP) is proposed to aggregate the capacities of RESs and facilitate the integration and management in a decentralized manner. In this paper, a novel framework for optimal energy management of VPP considering key features such as handling uncertainties with RESs, reducing operating costs and regulating system voltage levels is proposed, and a two-stage stochastic simulation is formulated to address the uncertainties of RESs generation and electricity prices. Simulation result show that the framework can benefit from ensuring the energy balance and system security, as well as reducing the operation costs.
\end{abstract}

\section{Keywords}

Virtual Power Plant, Renewable Energy Sources, Energy Management

\section{Introduction}

With environmental concerns and together with the increasing energy demand and limited supply of carbon-intensive fossil fuel, they have led to increased utilization of clean renewable energy resources (RESs), such as wind and solar power. Many governments have formulated renewable policies and standards to promote generation from RESs, which have resulted in a significant growth of renewable Distributed Generators (DGs) in many power systems [1].

However, the variable and uncertain nature of RES makes it difficult to manage and control in conventional power system. It has been observed that combining RESs with other conventional distributed generators as well as energy storage system (ESS), such as thermal plant, micro-CHP and battery storage system, can greatly address the power balancing and voltage regulating issue [2]. 
This aggregated cluster of resources improves the overall system reliability and is usually referred to as a Virtual Power Plant (VPP).

As described in [3], there are two types of VPP: commercial VPP (cVPP) and technical VPP (tVPP). A cVPP acts as a market agent and seeks to maximize its benefit from the portfolio without considering the network constraints, while a tVPP consists of some renewable DGs in the same geographical location and takes into account the real-time influence of the local network on the overall portfolio.

Depending on the type and penetration level of RES as well as market participation strategy, VPP energy management can be different from that of conventional power systems. Many works have been done to address the VPP energy management problem [4] [5] [6]. A prototype electrical energy management of VPP considering some RESs and ESSs is studied in [7], [8] proposed a stochastic energy management strategy for VPP with thermal and electrical generators and storage systems, and a coordination scheme for wind and micro-CHP that reduces the imbalance volumes and operating cost is introduced in [9]. However, none of the works mentioned above have fully considered the wind generation and ESSs in a detailed numerical way for tVPP energy management.

In this paper, we propose a comprehensive model for an optimal VPP energy management problem with wind generation, conventional distributed generators and ESSs within day-ahead and balancing market. The objective of the model is to minimize the VPP operating costs, including operation, maintenance and electricity market cost, while maintaining the energy balance and system security of the VPP. A two-stage stochastic approach to address the uncertainties in wind power outputs and electricity prices is introduced.

The main contribution of the paper are as follows: 1) A novel energy management model of VPP considering several important features including coordination of wind and conventional distributed generators, high penetration level of wind generation, and voltage regulation guarantees of power quality. 2) A two-stage stochastic optimization model to consider various uncertainties in VPP. The uncertainties lie in a two-settlement electricity prices, and RES power output. 3) Extensive simulations based on historical data sets is provided and results show that the stochastic approach is much better in reducing operating cost while maintaining system reliability.

The rest of the paper is organized as follow. Section 2 presents the system modeling. Section 3 formulates the optimization problem. Section 4 provides numerical results for the application, and finally section 5 concludes the paper.

\section{System Modeling}

\subsection{VPP Model}

In the proposed model, it is assumed that the VPP consists of micro-CHP units, wind turbines, battery storages as ESS units, inelastic loads. Micro-CHP units provide the overall energy efficiency, while wind turbines reduce carbon emissions. The uncertainty of wind power output can be overcome by coordinating 
with micro-CHP and battery storages. When real-time wind generation are different from the forecasted amount, batteries participate to mitigate the imbalance by charging or discharging.

The VPP is considered to be operated by a central controller, where owner can receive the forecasted information and has a direct control on each unit. The objective of the controller is to minimize the system operating costs. The VPP units are of close geographically proximity, and are connected to the main grid through a distribution line. The operating time is represented by $\mathrm{t}$ over $\mathrm{T}$ time slots, i.e. 24 hours with hourly time slots.

\subsection{Electricity Market Model}

The VPP model is assumed to participate into the power market similar to the Nordic Power Market [10], which is a competitive two-settlement electricity market including day-ahead market and real-time balancing market.

The central controller submits offer/bids for generation or consumption to the day-ahead market based on the whole profile's operational constraints and estimation. Due to the uncertainty, the real-time power exchange may be different from the power schedule. The central controller therefore needs to adjust the real-time power exchange to ensure the power balance. Moreover, when an imbalancing issue occurs, an upward regulation or downward regulation penalty will be paid in the balancing market.

\section{Problem Formulation}

The problem is formulated as a two-stage stochastic model. The first stage decision variables include unit commitment status of DG units and power bids in the day-ahead market. The second stage includes active and reactive power output of DG units, charging cycle of batteries, elastic load adjustment and real-time power exchanges in the balancing market.

\subsection{Objective Function}

The objective function, which is to minimize the overall operating costs, can be written as follow:

$$
\begin{gathered}
\min \sum_{i} \sum_{t}\left(\alpha_{i} p_{i, t}+\beta_{i}\right) \\
-\sum_{t}\left[p_{t}^{D A} \lambda_{t}^{D A}+\left(p_{t}^{B L}-P_{t}^{D A}\right) \lambda_{t}^{B L}-\varphi_{t}\left|p_{t}^{B L}-P_{t}^{D A}\right|\right] \\
+\sum_{k} \sum_{t} C_{k}\left(e_{k, t}^{-} / \eta_{k}^{-}+e_{k, t}^{+} \eta_{k}^{+}\right)
\end{gathered}
$$

The operation cost for the VPP is shown in Equation (1), where $\alpha_{i} p_{i, t}$ is the generation cost of micro-CHP unit $i$ at time $t$, and $\beta_{i}$ defines the no-load cost of unit $i$ at time $t$. The no-load cost incurs when unit $i$ is on.

Equation (2) describes the market cost for the VPP. The hourly bid and the real-time power exchange in the two-settlement market are $p_{t}^{D A}$ and $p_{t}^{B L}$, respectively. When $p_{t}^{D A}$ is positive/negative, the VPP is selling/buying power at a price of $\lambda_{t}^{D A}$ in the day-ahead market. In balancing market, the VPP is sell- 
ing/buying power with price $\lambda_{t}^{B L}$ as long as $\left(p_{t}^{B L}-p_{t}^{D A}\right)$ is positive/negative. The upward or downward regulation is defined as $\varphi_{t}\left|p_{t}^{B L}-p_{t}^{D A}\right|$, where a regulation $\varphi_{t}$ will be paid when the day-ahead power schedule and the real-time power exchange are not the same.

The cost of battery storage $\mathrm{k}$ is shown in Equation (3), where $e_{k, t}^{+}$and $e_{k, t}^{-}$ are the charging and discharging rate with efficiency $\eta_{k}^{+}$and $\eta_{k}^{-}$, respectively.

\subsection{Constraints}

1) Power Flow Equation. It is assumed that bus 1 is the swing bus and is connected to the main grid. The active and reactive power injection equation can be written as follows:

$$
\begin{gathered}
P_{j, t}=\sum_{i} p_{i, t}-p_{t}^{B L}-p_{j, t}^{L D}+\sum_{n} w_{n, t}+\sum_{k}\left(e_{k, t}^{-}-e_{k, t}^{+}\right), \forall t \\
Q_{j, t}=\sum_{i} q_{i, t}-q_{t}^{B L}-q_{j, t}^{L D}, \forall \mathrm{t}
\end{gathered}
$$

The net active power injection $P_{j, t}$ is the difference between the active power generation and load consumption. $p_{j, t}^{L D}$ denotes the load active power consumption at bus $j$, and $w_{n, t}$ represents the wind power output of unit $n$. Similarly, the net reactive power injection $Q_{j, t}$ equals to the difference of the reactive power generation and load reactive power consumption. The linearized power flow equations can be formulated as follow:

$$
\begin{gathered}
P_{j, t}=\left(2 V_{j, t}-1\right) G_{j, j}+\sum_{o(o \neq j)} G_{j, o}\left(V_{j, t}+V_{o, t}-1\right)+B_{j, o}\left(\theta_{j, t}-\theta_{o, t}\right), \forall t \\
Q_{j, t}=-\left(2 V_{j, t}-1\right) B_{j, j}+\sum_{o(o \neq j)}-B_{j, o}\left(V_{j, t}+V_{o, t}-1\right)+G_{j, o}\left(\theta_{j, t}-\theta_{o, t}\right), \forall \mathrm{t} \\
P_{j, o}^{t}=G_{j, o}\left(V_{j, t}-V_{o, t}\right)+B_{j, o}\left(\theta_{j, t}-\theta_{o, t}\right), \forall t \\
Q_{j, o}^{t}=B_{j, o}\left(V_{o, t}-V_{j, t}\right)+G_{j, o}\left(\theta_{j, t}-\theta_{o, t}\right), \forall t
\end{gathered}
$$

where $P_{j, o}^{t}$ and $Q_{j, o}^{t}$ are the active and reactive power flow over branch $(j, o)$, respectively. $V_{j, t}$ and $\theta_{j, t}$ represent the voltage magnitude and phase angle at bus $j$, respectively. $G_{j, o}$ and $B_{j, o}$ denote the real and imaginary parts of the VPP admittance matrix on branch $(j, o)$, respectively.

2) Network Constraints. For system security, the voltage magnitude and phase angle at each bus, as well as network congestion, are required to be in a safe operation interval. Hence, an upper and lower limits for voltage and power flow over branches are defined in Equations (10) and (11) respectively.

$$
\begin{aligned}
& V_{j}^{-} \leq V_{j, t} \leq V_{j}^{+}, \theta_{j}^{-} \leq \theta_{j, t} \leq \theta_{j}^{+}, \forall j, \forall t \\
& P_{j}^{-} \leq P_{j, o}^{t} \leq P_{j}^{+} Q_{j}^{-} \leq Q_{j, o}^{t} \leq Q_{j}^{+}, \forall j, \forall t
\end{aligned}
$$

3) Battery Storage Constraints: As the capacity of the battery storage lies in a certain operating range, to avoid over-charging or over-discharging, an upper and lower limits for the size of the batteries $E_{k, t}$ is defined respectively in the following two equations.

$$
\begin{gathered}
E_{k}^{-} \leq E_{k, t} \leq E_{k}^{+}, \forall k, \forall t \\
E_{k, t+1}=E_{k, t}+\left(e_{k, t}^{-} / \eta_{k}^{-}+e_{k, t}^{+} \eta_{k}^{+}\right), \forall k, \forall t
\end{gathered}
$$




\section{Case Study}

\subsection{Data}

The proposed VPP model is based on a modified IEEE 13-bus distribution test feeder (Figure 1) [11]. Three micro-CHP units are located on bus 6, 7 and 11, respectively, one wind turbine on bus 9 , and two battery storage systems on bus 2 and 10, respectively. The switch and transformer in the original test feeder are replaced by distribution lines. The base value of apparent power and voltage magnitude are set to be $5000 \mathrm{kVA}$ and $4.16 \mathrm{kV}$, respectively.

It is assumed that the VPP central control can receive the forecasted information and has a direct control over each unit. Table 1 shows the parameters of micro-CHP units, and the battery storage system data is given in Table 2. Historical data are gathered to describe the wind power [12], power demand [12] and the market prices [13], and are scaled down to meet the required install capacity.

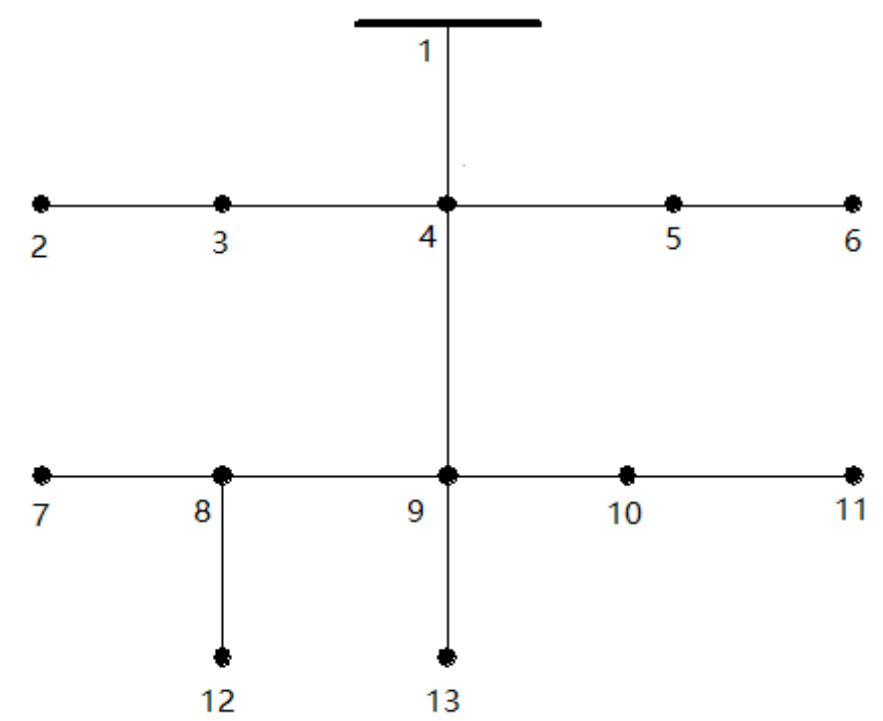

Figure 1. IEEE 13-bus distribution test feeder.

Table 1. Micro-CHP unit parameters.

\begin{tabular}{cccc}
\hline Unit & $\alpha_{i}(\$ / \mathrm{kWh})$ & $\beta_{i}(\$)$ & $\mathbf{P}_{\text {cap }}(\mathrm{kW})$ \\
\hline 1 & 0.15 & 30 & 1500 \\
2 & 0.30 & 50 & 1000 \\
3 & 0.50 & 70 & 1500 \\
\hline
\end{tabular}

Table 2. Storage parameters.

\begin{tabular}{cc}
\hline$E_{k}^{-}(\mathrm{kWh})$ & $E_{k}^{+}(\mathrm{kWh})$ \\
50 & $\mathrm{Max}=300$ \\
$e_{k, t}^{-}(\mathrm{kW})$ & $e_{k, t}^{+} \quad(\mathrm{kW})$ \\
100 & 100 \\
\hline
\end{tabular}




\subsection{Result}

1) Stochastic vs. Deterministic. A comparison study between the proposed stochastic approach and a deterministic approach to solve the VPP energy management problem is presented first. Figure 2 shows the simulation result. It can be observed that by increasing the wind penetration level, both approach benefit from reducing the system operating cost. This is because the wind turbine is assumed to have lower generation cost. Additionally, the result indicates that the performance of stochastic approach is better than deterministic approach, which ensures the better capability of stochastic approach in handling RES uncertainties.

2) Voltage Regulation. Power quality is one of the concerns in utilization of RES, and voltage regulation is one of the measurements for power quality. In this case, the upper and lower limits for voltage magnitude and phase angle are set to be \pm 0.5 p.u. and $\pm 0.03 \mathrm{rad}$, respectively, and the wind penetration is $20 \%$.

Figure 3 and Figure 4 presents the simulation results, and shows that both voltage magnitude and phase angle are in the safe operation interval.

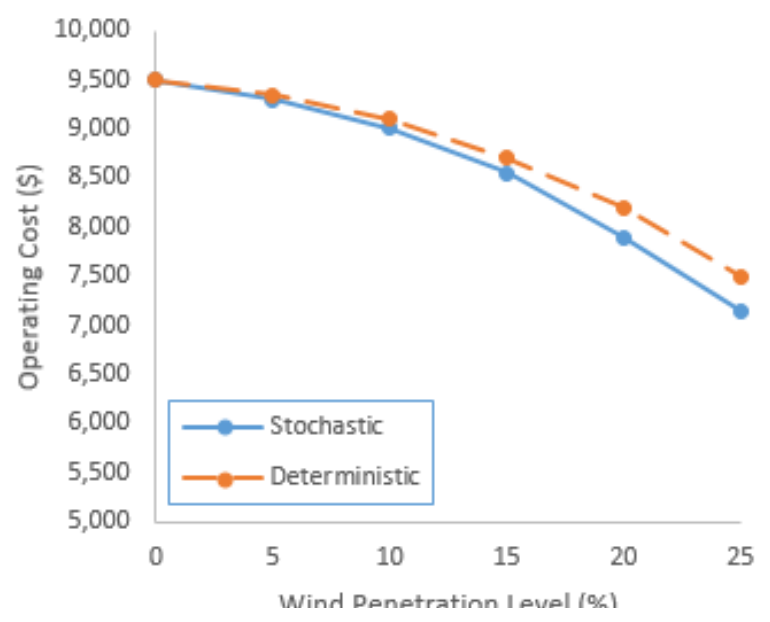

Figure 2. Operating cost with different wind penetration in stochastic vs. deterministic approach.

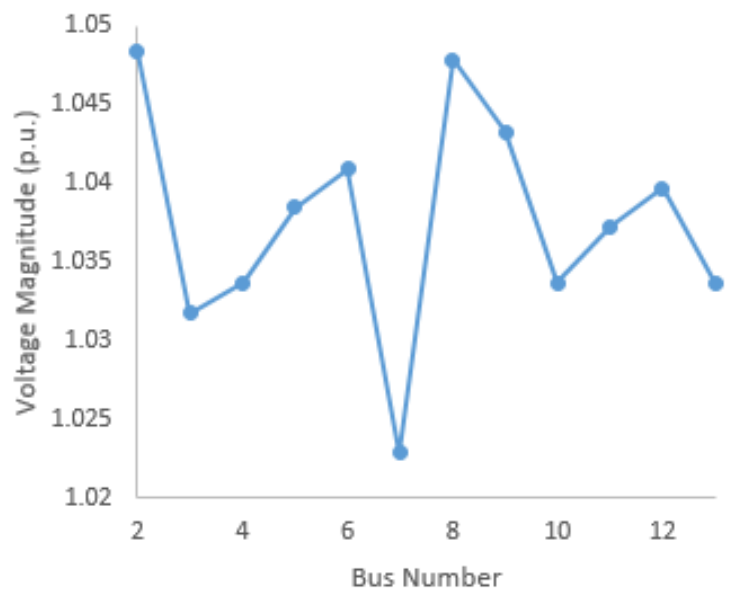

Figure 3. Voltage magnitude of each bus. 
3) Relation with Storage. In this case, the performance of ESS on uncertainty relief is evaluated. Comparison is made between the utilization of battery storage systems and without storages, and a daily storage capital cost is added into the storage system for further evaluation. The wind penetration is set to $20 \%$ and the energy efficiency of storage is set to $75 \%$. Figure 5 and Figure 6 shows the simulation results. It can be determined from Figure 5 that by adding ESSs into the VPP, the system operating cost is lower than that without ESS, which shows the performance of storages in mitigating power imbalance. In additional, In Figure 6, it can be observed that when adding the daily capital cost of storage, the most effective capacity of the storage system is $200 \mathrm{kWh}$. Therefore, an installing storage with capacity above $200 \mathrm{kWh}$ is uneconomic, since the storage itself will become more costly than profits.

\section{Conclusions}

This paper presents a novel energy management framework for VPP consisting of renewable power generation and energy storage system. The problem of

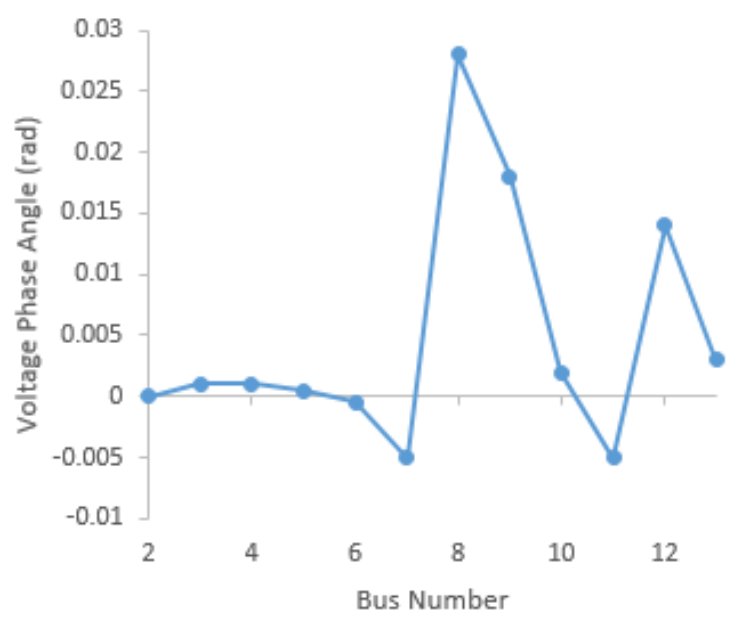

Figure 4. Voltage phase angle of each bus.

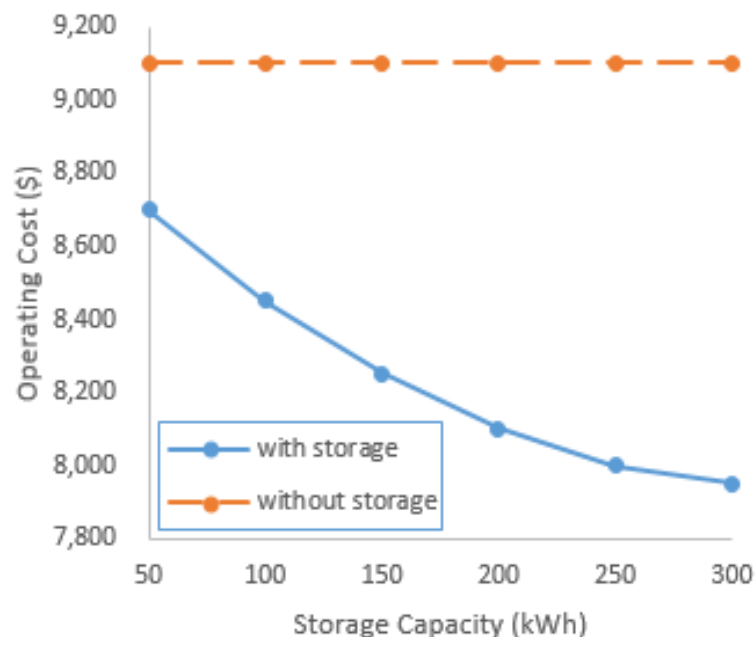

Figure 5. Cost vs. storage. 


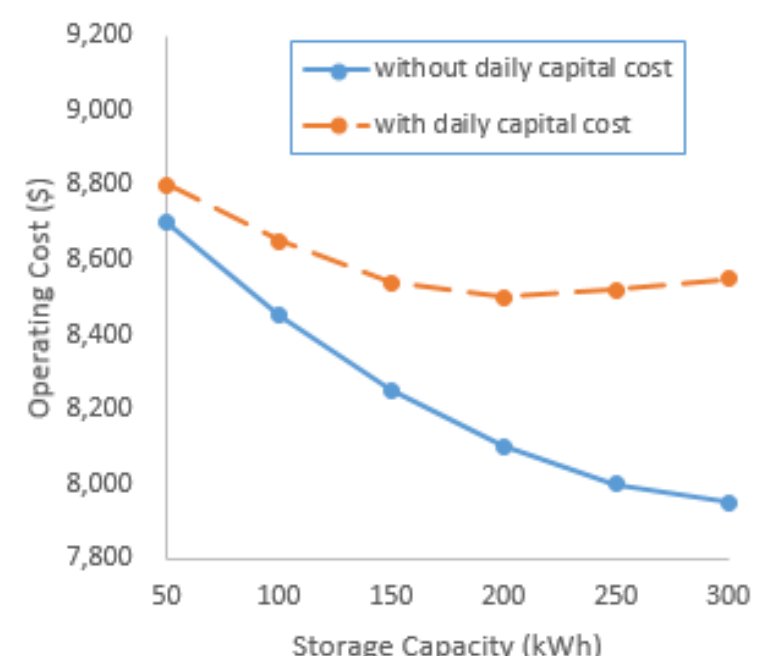

Figure 6. Cost (including capital) vs. storage.

minimizing the VPP's operating cost in both the day-ahead and balancing electricity market is formulated as a two-stage stochastic optimization problem. Extensive simulations have been conducted and results show the benefits of the framework in reducing the VPP's operating cost, while maintaining power quality and system security.

Suggestions for future research include consideration of bidding strategy in the stochastic optimization, as well as increasing numbers of input scenarios to test the stability of the results and solve different subproblems in parallel.

\section{Acknowledgements}

Y. Kang thanks to Prof. Kwoklun Lo and Dr Ivana Kockar for supervising the research project. I would also thank to my parents, who gives me fully support during my study.

\section{References}

[1] (2013) Renewables 2014 Global Status Report. Renewable Energy Policy Network for the 21st Century (REN21), Paris, France, Tech. Rep. GSR2014.

[2] Lombardi,P.,Powalko, M.and K. Rudion.(2009) Optimal Operation of a Virtual Power Plant.IEEE Power Energy Society General Meeting. 6. https://doi.org/10.1109/pes.2009.5275995

[3] Pudjianto,D., Ramsay,C.,Strbac, G. and Durstewitz, M.(2008) TheVirtual Power Plant: Enabling Integration of Distributed Generation and Demand.FENIX Bull. 2. http://fenix.iwes.fraunhofer.de/docs/public/2008_02_01_FENIX_bulletin_No_2.pdf

[4] Pudjianto,D., Ramsay,C. andStrbac, G. (2007) Virtual power plant and system integration of distributed energy resources. IET Renewable Power Generation, 1.

[5] Salmani,M.A.,Anzalchi,A. and Salmani,S.(2010) Virtual Power Plant: New Solution for Managing Distributed Generations in Decentralized Power Systems. 2010 International Conference on Management and Service Science, 1-6. https://doi.org/10.1109/ICMSS.2010.5577383

[6] Aloini, D., Crisostomi, E., Raugi, M. and Rizzo, R. (2011) Optimal Power Scheduling in a Virtual Power Plant. 2011 2nd IEEE PES International Conference and Exhibi- 
tion on Innovative Smart Grid Technologies, 1-7.

https://doi.org/10.1109/isgteurope.2011.6162768

[7] Nezamabadi,P. and Gharehpetian, G. B. (2011) Electrical Energy Management of Virtual Power Plants in Distribution Networks with Renewable Energy Resources and Energy Storage Systems. 16 th Electrical Power Distribution Conference, 1-5.

[8] Giuntoli,M. and Poli, D.(2013) Optimized Thermal and Electrical Scheduling of a Large Scale Virtual Power Plant in the Presence of Energy Storages.IEEE Transactions on Smart Grid, 4, 942-955.https://doi.org/10.1109/TSG.2012.2227513

[9] Houwing,M.,Papaefthymiou,G.,Heijnen, P. W. and Ilic, M. D. (2009) Balancing Wind Power with Virtual Power Plants of Micro-CHPs. 2009 IEEE Bucharest PowerTech, 1-7.

[10] Asa.N. P. (2004). The Nordic Power Market. http://www.fer.unizg.hr/_download/repository/Nord\%20Pool\%20-\%20The\%20Nor dic\%20Power\%20Market.pdf

[11] IEEE 13-bus Distribution Test Feeder. https://ewh.ieee.org/soc/pes/dsacom/testfeeders/

[12] Elia.(2016) Belgium's Electricity Transmission System Operator. http://www.elia.be/en/grid-data/power-generation/wind-powerhttp://www.elia.be/e n/grid-data/Load-and-Load-Forecasts/total-load\#01

[13] The Nord Pool. http://www.nordpoolspot.com/

\section{Submit or recommend next manuscript to SCIRP and we will provide best} service for you:

Accepting pre-submission inquiries through Email, Facebook, LinkedIn, Twitter, etc. A wide selection of journals (inclusive of 9 subjects, more than 200 journals)

Providing 24-hour high-quality service

User-friendly online submission system

Fair and swift peer-review system

Efficient typesetting and proofreading procedure

Display of the result of downloads and visits, as well as the number of cited articles

Maximum dissemination of your research work

Submit your manuscript at: http://papersubmission.scirp.org/

Or contact epe@scirp.org 